Provided for non-commercial research and education use. Not for reproduction, distribution or commercial use.



This article appeared in a journal published by Elsevier. The attached copy is furnished to the author for internal non-commercial research and education use, including for instruction at the authors institution and sharing with colleagues.

Other uses, including reproduction and distribution, or selling or licensing copies, or posting to personal, institutional or third party websites are prohibited.

In most cases authors are permitted to post their version of the article (e.g. in Word or Tex form) to their personal website or institutional repository. Authors requiring further information regarding Elsevier's archiving and manuscript policies are encouraged to visit:

http://www.elsevier.com/copyright 
Short Communication

\title{
The General Factor of Personality and its relation to Self-Esteem in 628,640 Internet respondents
}

\author{
Stephen Erdle ${ }^{\mathrm{a}, *}$, Paul Irwing ${ }^{\mathrm{b}}$, J. Philippe Rushton ${ }^{\mathrm{c}}$, Jane Park ${ }^{\mathrm{b}}$ \\ ${ }^{a}$ Huron University College at the University of Western Ontario, Canada N6G 1 H3 \\ ${ }^{\mathrm{b}}$ University of Manchester, UK \\ ${ }^{\mathrm{c}}$ University of Western Ontario, Canada
}

\section{A R T I C L E I N F O}

\section{Article history:}

Received 26 May 2009

Received in revised form 31 August 2009

Accepted 7 September 2009

Available online 2 October 2009

\section{Keywords:}

Self-Esteem

Personality

Big Five

General Factor of Personality

\begin{abstract}
A B S T R A C T
The purpose of this study was to explore the relationship between the General Factor of Personality (GFP) and Self-Esteem. We found a GFP that explained $57 \%$ of the reliable variance in a model that went from the Big Five to the Big Two to the Big One in a secondary analysis of a sample of 628,640 participants, reported by Erdle, Gosling, and Potter (2009) using an interactive website on the Internet. The GFP in turn accounted for $67 \%$ of the variance in the measure of Self-Esteem. We discuss alternative possibilities to account for the relationship.
\end{abstract}

(c) 2009 Elsevier Ltd. All rights reserved.

\section{Introduction}

A recent hypothesis is that a General Factor of Personality (GFP) occupies the apex of the hierarchy of personality. The main empirical impetus for identifying the GFP has come from the positive manifold manifest among personality scales. When Digman (1997) examined 14 sets of inter-scale correlations from the Big Five, he found the average correlation was .26. He extracted two reliable higher-order factors: Alpha (Agreeableness, Conscientiousness, Emotional Stability) and Beta (Extraversion, Openness), which he associated with socialization processes and personal growth, respectively. Subsequently, DeYoung (2006) replicated Digman's two-factor solution and re-labeled Alpha as Stability and Beta as Plasticity, which he linked to the serotonergic and dopaminergic systems, respectively. Both Digman and DeYoung contended there is no higher-order General Factor of Personality.

Subsequently, however, both Musek (2007) and Rushton and Irwing $(2008,2009)$ found a GFP in the Big Five. For example, Rushton and Irwing (2008) used structural equation modeling (SEM) and extracted a very clear GFP from two meta-analyses. In the first meta-analysis, a GFP explained $45 \%$ of the reliable variance in a model that went from the Big Five to the Big Two to the Big One in the 14 sets of inter-scale correlations $(N=4496)$ assembled by

\footnotetext{
* Corresponding author. Address: Huron University College at the University of Western Ontario, 1349 Western Road, London, ON, Canada N6G 1H3. Tel.: +1 519 438 7224x225; fax: +1 5194383938.
}

E-mail address: serdle@uwo.ca (S. Erdle).
Digman (1997) to establish the Big Two. Higher-order Alpha was defined by Conscientiousness, Emotional Stability, and Agreeableness, with loadings of from .61 to .70, while Beta was defined by Openness and Extraversion, with loadings of .55 and .77. In turn, the GFP was defined by Alpha and Beta with loadings of .67. In the second meta-analysis, the above model was confirmed with a GFP that explained $44 \%$ of the variance using data from a published meta-analysis of four alternative measures of the Big Five $(N=4000)$. This model was further cross-validated by a meta-analysis of the inter-scale correlations of 16 studies (Total $N=6412$ ) assembled from five published studies by DeYoung and colleagues (Rushton \& Irwing, 2009).

The GFP was found to be independent of method variance in a multitrait-multimethod analysis of self-, teacher-, and parent-ratings of 391 13- to 14-year-olds on the Big Five Questionnaire Children (Rushton et al., 2009). Several cross-national twin studies have found $50 \%$ of the variance on the GFP attributable to genetic influence and $50 \%$ to non-shared environmental influence, including of 322 pairs of adult twins from the UK, 575 pairs of 2- to 9year-old twins from South Korea, 651 twin pairs from Japan, and 386 twin pairs from Canada and the US (Rushton, Bons, \& Hur, 2008; Rushton et al., 2009; Veselka, Schermer, Petrides, \& Vernon, 2009). The South Korean twin data showed the GFP had emerged by 2- to 3-years of age (Rushton et al., 2008). Another of the twin studies linked the GFP through the Big Five to Trait Emotional Intelligence (Veselka et al., 2009).

The present investigation examined whether the GFP could be found in a very large sample of Big Five data and explored its 
relation to self-esteem. Individuals high on the GFP have already been characterized as altruistic, emotionally stable, agreeable, conscientious, extraverted, and intellectually open, with high levels of well-being, satisfaction with life, self-esteem, and emotional intelligence (Musek, 2007; Rushton et al., 2008). We re-analyze the data published by Erdle, Gosling, and Potter (2009) on the relation of self-esteem and the Big Five Inventory (BFI). They found significant correlations between all six measures and a principal components analysis showed self-esteem loaded on the higher-order factors of Stability (.41) and Plasticity (.39). Although a correlation was also found of .24 between Plasticity and Stability, the authors did not test for the higher-order GFP.

\section{Method}

\subsection{Participants}

Participants were 628,640 people who completed the self-report questionnaires using an interactive website on the Internet (Erdle et al., 2009; Gosling et al., 2004). Participants were residents of the USA (55\% women) and ranged in age from 9 to 90 (Median $=24, \mathrm{SD}=9.8$ ) (Rentfrow, Gosling, \& Potter, 2008).

\subsection{Measures}

The personality factors were measured using the Big Five Inventory (BFI: John \& Srivastava, 1999). The BFI is a 44-item self-report measure comprised of short items assessing the Big Five personality factors. Items are responded to on a 5-point scale ranging from "strongly disagree" to "strongly agree." Self-Esteem was measured by the Single-Item Self-Esteem Scale (SISE: Robins, Hendin, \& Trzesniewski, 2001). The item "I see myself as someone who has high self-esteem" was rated on a 5-point scale ranging from "strongly disagree" to "strongly agree". The SISE has been found to have high test-retest reliability, criterion validity coefficients above .80 (median $=.93$ after correcting for unreliability) with the Rosenberg Self-Esteem Scale (RSE), and a similar pattern of construct validity coefficients as the RSE with 37 different constructs (Robins et al., 2001). Using longitudinal data, Robins et al. (2001) estimated the reliability of the SISE to be .75 .

\subsection{Strategy of analysis}

We follow a close approximation to the ideal strategy outlined by Jöreskog (1993) for model testing. Designated "strictly confirmatory," it is only rarely approximated. Prior theory and research point to the correctness of a single model, which is then tested in a representative sample. If confirmed, it can be concluded that the model is generalizable. Rushton and Irwing $(2008,2009)$ have shown that a single model of the higher-order factor structure of the Big Five held in three different meta-analyses of sets of Big Five inter-scale correlations. We will examine whether it holds in the present data set and explore its relation to Self-Esteem.

\section{Results}

Table 1 shows the inter-scale correlations for the measure of Self-Esteem and the Big Five Factors. The mean correlation between all six variables was $r=.23$.

To test each model, we performed a series of confirmatory factor analyses using LISREL 8.72 (Jöreskog \& Sorbom, 2001). In order to evaluate model fit we relied mainly on the standardized root mean square residual (SRMSR), the root mean square error of approximation (RMSEA), and the non-normed fit index (NNFI), as indicated by the simulations of $\mathrm{Hu}$ and Bentler $(1998,1999)$, and we also
Table 1

Correlations among BFI scales and Self-Esteem (from Erdle, Gosling, \& Potter, 2009).

\begin{tabular}{llllll}
\hline & E & A & C & ES & Self-Esteem \\
\hline O & .19 & .09 & .07 & .08 & .18 \\
E & & .15 & .12 & .26 & .40 \\
A & & & .26 & .30 & .13 \\
C & & & & .27 & .26 \\
ES & & & & & .48 \\
\hline
\end{tabular}

Note. $\mathrm{O}=$ Openness to Experience; $\mathrm{E}=$ Extraversion; $\mathrm{A}=$ Agreeableness; $\mathrm{C}=\mathrm{Con}-$ scientiousness; ES = Emotional Stability.

examined chi-squares and chi-square differences following the recommendations of Jöreskog (1993). We adopted cut-off points of $\leqslant .05$ for the SRMSR, about .06 for the RMSEA, and $\geqslant .95$ for the NNFI.

The third-order factor model incorporating the GFP provided an excellent fit to the data according to both the RMSEA and SRMSR, while the NNFI was just shy of close fit (see Fig. $1 \mathrm{~A}, \chi^{2}=6123.05$; $d f=4 ; P<.001 ; \mathrm{NNFI}=.94 ;$ RMSEA $=.050 ;$ SRMSR $=.020)$. In order to provide an unequivocal test of the existence of a general factor, an alternative version of the model was examined in which the Big Two were specified to be uncorrelated. Notably, this latter model provided a very poor fit to the data $\left(\chi^{2}=52,124.7 ; d f=6\right.$; NNFI = .65; RMSEA $=.12$; SRMSR $=.09$ ). There was no plausible alternative to a model without a general factor. The model explains $57 \%$ of the variance in the factors of Stability and Plasticity, i.e. 57\% of the reliable variance. However, because there is substantial error in most of the indicators, this only translates into $15 \%$ of the scale level variance.

In order to assess the construct validity of the GFP, we tested a modified version of Model 1A, whereby Self-Esteem was added as an indicator of the GFP. Because the measure of Self-Esteem comprised a single item, it was not possible to estimate measurement error. For this reason, we set the loading of the latent variable on the observed variable of Self-Esteem to 1, and the measurement error to zero. The fit indices for the new model showed a dramatic decrease in model fit, with only the SRMSR meeting the criterion for close fit $\left(\chi^{2}=32971.04 ; d f=7 ; P<.001 ; \mathrm{NNFI}=.87\right.$; RMSEA $=$ .084 ; SRMSR $=.036$ ). Inspection of the modification indices suggested that allowing a factor loading of Agreeableness on Self-Esteem would lead to a substantial improvement in fit. We therefore tested a model in which this loading of Agreeableness on Self-Esteem was permitted. The revised model provided an excellent fit to the data $\left(\chi^{2}=7863.35 ; d f=6 ; P<.001 ; \mathrm{NNFI}=.97\right.$; RMSEA $=.045$; SRMSR $=.020$ ). Nevertheless, there was still a substantial modification index for the effect of Self-Esteem on Emotional Stability. Allowing this path provided a substantial improvement in fit $\left(\chi^{2}=3424.14 ; d f=5 ; P<.001 ; \mathrm{NNFI}=.98\right.$; RMSEA $=.033$; SRMSR $=.012$ ). Therefore, this model was our preferred solution (see Fig. 1B). The loading of Self-Esteem on the GFP, at .82 , was very substantial.

\section{Discussion}

We found strong confirmatory evidence that the Big Five load on the two first-order factors of Stability (Emotional Stability, Agreeableness, Conscientiousness) and Plasticity (Extraversion, Openness), which in turn load strongly on a General Factor of Personality. The existence of the GFP was unequivocally demonstrated since the model which did not include a general factor provided a very poor fit to the data. We also found that the GFP and Self-Esteem share $67 \%$ of common variance. Indeed it could even be concluded that in this sample, the GFP is mostly Self-Esteem, since the two constructs share $67 \%$ of common variance. We also found a 
Panel A
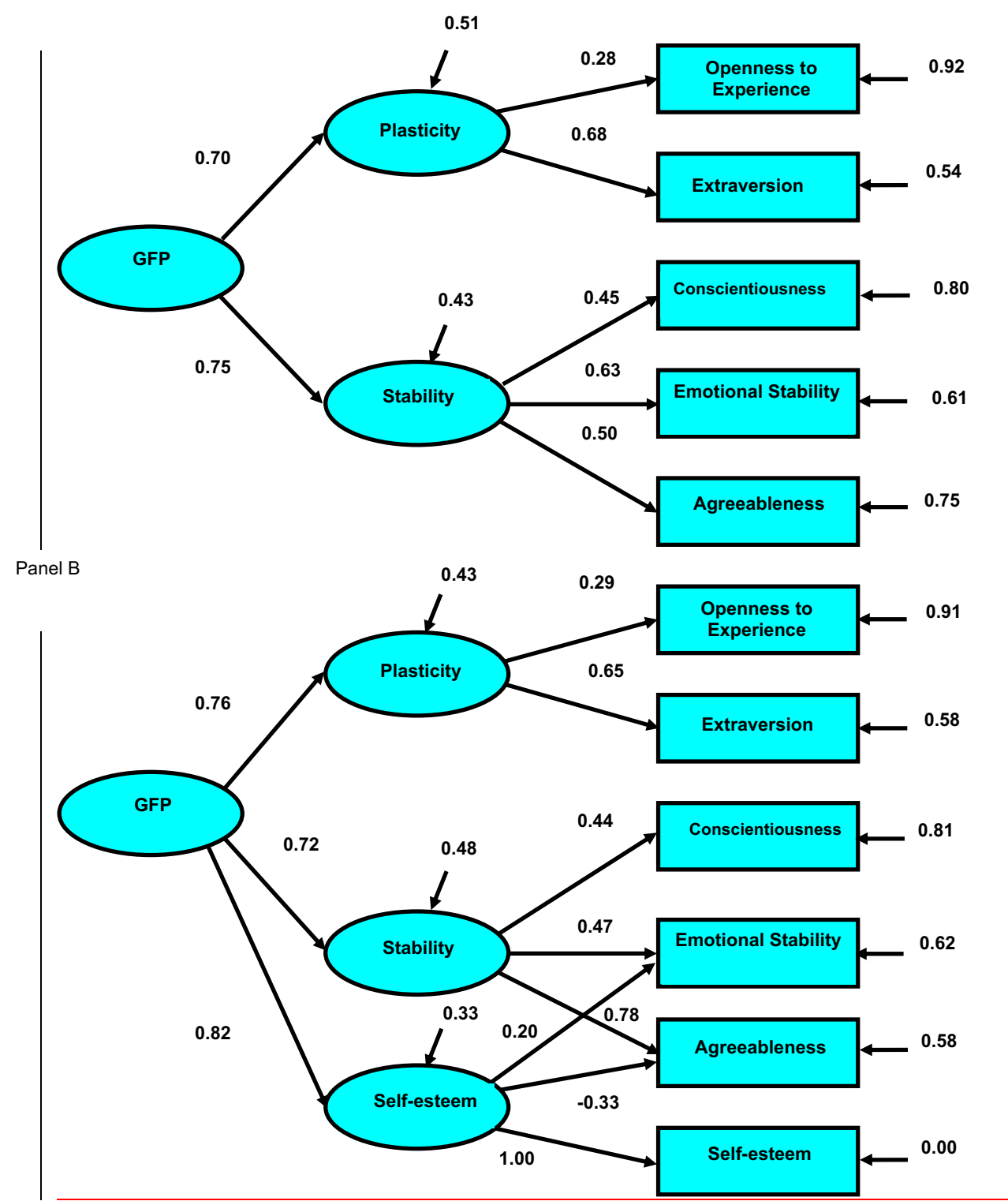

Fig. 1. Panel A: Standardized confirmatory factor model of the structural hierarchy of personality from the Big Five through the Big Two to the GFP. Panel B: Standardized confirmatory factor model of the structural hierarchy of personality from the Big Five through the Big Two to the GFP, including Self-Esteem.

negative loading (-.33) of Agreeableness on Self-Esteem, which might imply that in this sample, once the positive relationship between the GFP and both Agreeableness and Self-Esteem is controlled for, that the remaining effect of Self-Esteem is negative. That is, once the effects of the GFP are removed, then high Self-Esteem is associated with lesser Agreeableness, possibly because people with high self-esteem feel less of a need to ingratiate themselves. Similarly, self-esteem appears to have a small positive effect (.20) on Emotional Stability, after controlling for the effects of the GFP. This finding is consistent with the well established prophylactic effect of self-esteem on depression.

A limitation of our analysis is that we were unable to correct for measurement error in the single item measure of Self-Esteem. This means that we may have underestimated the loading of Self-Esteem on the GFP, and similarly underestimated its effects on Agreeableness and Emotional Stability.

Numerous interpretations are possible for the findings. The one we favor is that the GFP and self-esteem have arisen jointly through natural selection for adaptive personality traits (Rushton et al., 2008). Adaptive personality traits are traits that facilitate competent performance across a broad range of important contexts. Another interpretation is that the GFP and its relationship with Self-Esteem arise as an artifact due to self-evaluative biases (Bäckstrom, Bjorklund, \& Larsson, 2009). Only further research will determine which of these (and other) hypotheses is correct.

\section{References}

Bäckstrom, M., Bjorklund, F., \& Larsson, M. R. (2009). Five-factor inventories have a major general factor related to social desirability which can be reduced by framing items neutrally. Journal of Research in Personality, 43, 335-344.

DeYoung, C. G. (2006). Higher-order factors of the Big Five in a multi-informant sample. Journal of Personality and Social Psychology, 91, 1138-1151.

Digman, J. M. (1997). Higher-order factors of the Big Five. Journal of Personality and Social Psychology, 73, 1246-1256.

Erdle, S., Gosling, S. D., \& Potter, J. (2009). Does Self-Esteem account for the higherorder factors of the Big Five? Journal of Research in Personality, 43, 921-922. 
Gosling, S. D., Vazire, S., Srivastava, S., \& John, O. P. (2004). Should we trust webbased studies? A comparative analysis of six preconceptions about Internet questionnaires. American Psychologist, 59, 93-104.

Hu, L.-T., \& Bentler, P. M. (1998). Fit indices in covariance structural modeling. Psychological Methods, 3, 424-453.

Hu, L.-T., \& Bentler, P. M. (1999). Cutoff criteria for fit indices in covariance structure modeling: Conventional criteria versus new alternatives. Structural Equation Modeling, 6, 1-55

John, O. P., \& Srivastava, S. (1999). The Big Five trait taxonomy: History measurement, and theoretical perspectives. In L. A. Pervin \& O. P. John (Eds.) Handbook of personality: Theory and research (2nd ed., pp. 102-138). New York, NY: Guilford Press.

Jöreskog, K. G. (1993). Testing structural equation models. In K. A. Bollen \& J. S. Long (Eds.), Testing structural equation models (pp. 294-316). London: Sage.

Jöreskog, K. G., \& Sorbom, D. (2001). LISREL 8: User's reference guide. Chicago, IL: Scientific Software International.

Musek, J. (2007). A general factor of personality: Evidence for the Big One in the five-factor model. Journal of Research in Personality, 41, 1213-1233.

Rentfrow, P. J., Gosling, S. D., \& Potter, J. (2008). A theory of the emergence, persistence, and expression of geographic variation in psychological characteristics. Perspectives on Psychological Science, 3, 339-369.
Robins, R. W., Hendin, H. M., \& Trzesniewski, K. (2001). Measuring global Self-Esteem: Construct validation of a single-item measure and the Rosenberg Self-Esteem Scale. Personality and Social Psychology Bulletin, 27, 151-161.

Rushton, J. P., Bons, T. A., Ando, J., Hur, Y.-M., Irwing, P., Vernon, P. A., et al. (2009). A general factor of personality from multitrait multimethod data and crossnational twins. Twin Research and Human Genetics, 12, 356-365.

Rushton, J. P., Bons, T. A., \& Hur, Y.-M. (2008). The genetics and evolution of a general factor of personality. Journal of Research in Personality, 42, $1173-1185$.

Rushton, J. P., \& Irwing, P. (2008). A general factor of personality from two meta-analyses of the Big Five: Digman (1997) and Mount, Barrick, Scullen, and Rounds (2005). Personality and Individual Differences, 45, 679-683.

Rushton, J. P., \& Irwing, P. (2009). A general factor of personality in 16 sets of the Big Five, the Guilford-Zimmerman Temperament Survey, California Psychological Inventory, and Temperament and Character Inventory. Personality and Individual Differences, 47, 558-564.

Veselka, L., Schermer, J. A., Petrides, K. V., \& Vernon, P. A. (2009). Evidence for a heritable general factor of personality in two studies. Twin Research and Human Genetics, 12, 254-260. 